\title{
A CORRELAÇÃO ENTRE NORMA E IMPUTAÇÃO OBJETIVA EM GÜNTHER JAKOBS
}

\section{Diego Alan Schöfer Albrecht}

Doutorando e mestre em Ciências Criminais pela PUCRS. Coordenador do Curso de Direito da FAl Faculdades de Itapiranga-SC, na qual também coordena o grupo de pesquisa "Ciências Criminais na Contemporaneidade: diálogos entre criminologia, dogmática penal e política criminal". Professor de Criminologia, Direito Penal e Direito Processual Penal. Advogado. diea2110@yahoo.com.br

\section{Marcos Afonso Johner}

Acadêmico do curso de Graduação em Direito da FAl - Faculdades de Itapiranga-SC. Integrante do grupo de pesquisa "Ciências Criminais na Contemporaneidade: diálogos entre criminologia, dogmática penal e política criminal". marcosjohner@yahoo.com.br

\section{Resumo:}

0 objetivo precípuo do presente trabalho é verificar qual a necessária correlação entre norma e imputação objetiva no modelo funcional-sistêmico de Günther Jakobs, com o fito de determinar o real alcance do nexo causal e constatar quando é necessária a aplicação de uma pena. 0 estudo em tela reveste-se de extrema importância na atual discussão dogmática do Direito Penal, haja vista que o modelo de Jakobs reinventa a estruturação da teoria do crime, que passa a ser analisada a partir de uma sociedade concreta, e não imaginária, sustentada em expectativas sociais generalizadas na forma de normas. Utilizou-se de pesquisa bibliográfica para a discussão e aprofundamento teórico do assunto delimitado. 0 estudo da teoria da pena de Jakobs, portanto, é de relevada importância para 0 aprofundamento e desenvolvimento da dogmática penal, pois apresenta novas formas de trabalhar com os acontecimentos humanos essenciais para a ciência criminal, acrescendo fundamentos e critérios que proporcionam uma forma mais concreta de pensar e fazer o Direito Penal.

\section{Palavras-chave:}

Sociedade. Expectativas. Norma. Vigência. Imputação objetiva. 


\title{
THE CORRELATION BETWEEN NORM AND OBJECTIVE IMPUTATION IN GÜNTHER JAKOBS
}

\begin{abstract}
:
The principal objective from the present job is to verify which the necessary correlation between norm and objective imputation in the type systemic-funcional of the Günther Jakobs, with the aim of to determine de real extent from the causal link and to check is necessary the application of a penalty. This study is very important in the current dogmatic discussion of the Criminal Law, because the Jakobs model reinvent the crime theory structuration, which is analyzed from a concrete society, and not imaginary, sustained in social expectancy generalized in the norm form. Was used bibliography research from the discussion and theoretical deepening to the subject bounded. Therefore, the study of the punishment theory by Jakobs is very important for the deepening and development from the criminal dogmatic, since show new work form's, for it presents new ways of working with human events relevant to a criminal science, adding grounds and criteria that provide a more concrete way of thinking and doing Criminal Law.
\end{abstract}

\section{Keywords:}

Society. Expectations. Norm. Validity. Objective imputation.

Recebido em: 21/6/2017

Aceito em: 21/9/2017

\section{Sumário:}

1 Introdução. 20 direito como sistema autopoiético. 30 funcionalismo sistêmico no Direito Penal. $4 \mathrm{~A}$ imputação objetiva como realização da ação. $5 \mathrm{~A}$ correlação entre norma e imputação objetiva. 6 Conclusão. 7 Referências. 


\section{INTRODUÇÃO}

A estrutura dogmática da teoria do delito passou, no trasladar dos milênios, por uma intensa reformulação. A renovação - e inovação - no tratamento ao tipo objetivo, mormente a imputação e a nova ideia de nexo de causalidade a ele inerente, é um dos principais contributos dessa nova perspectiva de trabalho no âmbito dogmático.

Günther Jakobs, catedrático da Universidade de Bonn, na Alemanha, é um dos responsáveis por essa nova concepção do Direito Penal. Seus estudos e conclusões são de extrema relevância, na medida em que reinventam a forma de pensar a dogmática penal. Discípulo de Welzel, não se limitou às ideias de seu tutor, indo além, abandonando os subjetivismos da teoria finalista da ação e incrementando, no tipo objetivo, novos institutos que servem de parâmetro para aferir a tipicidade do comportamento.

Além disso, estruturou seu pensamento a partir da teoria sistêmica de Niklas Luhmann, edificando sua teoria da pena a partir de expectativas generalizadas de comportamento, que conferem papéis sociais a cada pessoa componente da sociedade. Em razão disso, sua corrente dogmática ficou conhecida como funcionalismo-sistêmico, que, ademais da adaptação luhmanniana, lastreia-se em critérios de prevenção geral positiva.

Este estudo abrangerá, sem pretensão de esgotamento, o modelo funcional-sistêmico arquitetado por Günther Jakobs. Demonstrar-se-á, prima facie, a visão da sociedade e do Direito em Niklas Luhmann, posto que de fundamental importância para compreender a estrutura dogmática proposta por Jakobs. Em seguida, analisar-se-á a função da pena e da norma na ótica jakobsiana, cuja criteriologia remete-se à prevenção geral positiva. Posteriormente, discorrer-se-á sobre a imputação objetiva do comportamento, como fator de realização da conduta humana. Por derradeiro, será estabelecida a necessária correlação entre norma e imputação objetiva. 


\section{DIREITO COMO SISTEMA AUTOPOIÉTICO}

O sociólogo Niklas Luhmann é responsável pela compreensão sistêmica da sociedade, ${ }^{1}$ considerando-a como um sistema complexo, que surge a partir da diferenciação deste em relação ao seu entorno. Assim, os elementos dependência e independência coexistem como faces de uma mesma moeda no conjunto entorno-sistema (LUHMANN, 2007). Em outras palavras, "a dependência deriva do fato de o sistema emergir do meio, entretanto, o sistema adquire independência em razão do seu desenvolvimento, pautado na inclusão de relaçóes autorreferenciais, produzindo uma espécie de auto-organização" (PORTUGAL, 2013, p. 4).

O surgimento de um sistema, de acordo com Luhmann, passa por dois momentos distintos: o da diferenciação, quando adquire autonomia, destacando-se do entorno que lhe deu origem, e o da indeterminação, quando o interior do sistema se compatibiliza com a capacidade de se auto-organizar.

Vale dizer, o sistema se origina em razão do passado, isto é, do entorno, mas com vistas à produção de efeitos futuros, de auto-organização. Dito isso, o sistema pode ser comparado a um ovo. A casca, em especial seu interior, representa o entorno, ao passo que os elementos interiores, a clara e a gema, representam o sistema. No momento em que o ovo é quebrado, ocorre a diferenciação, instante em que clara e gema adquirem autonomia. Logo, ambas podem se auto-organizar - espaço de indeterminação. $\mathrm{O}$ ovo determina o surgimento da clara e da gema, mas não o seu desenvolvimento.

É a partir de então que Luhmann aplica a ideia de autopoiese - do grego "autós" (por si próprio), mais “poiesis" (criação, produção) (NADER, 2014, p. 227) aos sistemas - e posteriormente ao Direito - em virtude de sua atuação dinâmica, isto é, ligados tanto ao passado quanto ao futuro. Autopoiético é o sistema que produz não apenas sua própria estrutura, mas, também, os elementos que nele estão constituídos (LUHMANN, 2007).

1 Convém anotar que Luhmann não é o único pesquisador que aplicou a teoria dos sistemas à sociedade. Entre os autores que debateram o tema destaca-se Talcott Parsons, que inclusive influenciou Luhmann em suas primeiras pesquisas. Além dele, pode-se mencionar Ludwig von Bertalanffy, cuja teoria dos sistemas influenciou sobremaneira a Teoria Geral da Administração. 
Além do mais, o sistema autopoiético é, simultaneamente, aberto e fechado, pois "sincroniza a repetição e a diferença, tendo que equacionar no seu interior esse paradoxo que os operadores do Direito vão usar como critério para tomar decisóes" (ROCHA; SCHWARTZ; CLAM, 2013, p. 36). Leonel Severo Rocha acrescenta:

É um sistema que não é fechado nem aberto. Por quê? Porque um sistema fechado é impossível, não pode haver um sistema que se autorreproduza somente nele mesmo. Por sua vez, igualmente, não pode haver um sistema totalmente aberto e sem limites. Há, aqui, então, a proposta da autopoiese que estabelece um critério de repetição e diferença simultânea (ROCHA; SCHWARTZ; CLAM, 2013, p. 36).

No mesmo raciocínio os ensinamentos de André Trindade:

O sistema jurídico, sob a ótica da autopoiese, e seguindo os ditames dessa, pode ser considerado como um sistema ao mesmo tempo aberto e fechado. Aberto às influências do meio externo que passam pelo processo de seleção realizado pelo código direito/não direito, juridicizando os elementos do meio que passam a integrar sua estrutura e servem de aparato para a manutençấo da sua auto-referencialidade (sic passim). Fechado no sentido de auto-referencialidade operativa, isso é, o direito se auto-regula através da sua identidade (código binário) (2007, p. 124).

Dessa forma, o Direito, numa perspectiva autopoiética, é abalizado como autorreferente. Isso significa que ele origina os próprios mecanismos de (auto)reprodução, a partir do momento em que se diferencia do entorno que lhe conferiu realidade. Consequentemente, a autorreferência concretiza-se por meio de movimentos fechados e circulares, fenômeno chamado de clausura operacional. Vide, a propósito, as liçóes de Leonel Severo Rocha:

Destarte, o sistema jurídico, como um sistema autopoiético, apresenta-se ante uma interação autorreferente, recursiva e circular de seus elementos internos (fechamento operacional), os quais, por isso, não apenas se auto-organizam, mas, também, se autoproduzem; isto é, produzem os elementos necessários para 
a sua reprodução. Assim, suas condições originárias tornam-se independentes do meio envolvente e possibilitam sua própria evolução (grifamos) (ROCHA; SCHWARTZ; CLAM, 2013, p. 41).

Doravante, o fenômeno jurídico é classificado como um sistema parcial ou de segundo grau, decorrente da absorção de elementos do sistema social (circuito comunicativo geral), que fornecerá ao subsistema os elementos necessários para sua autopoiese. Desse processo, então, advém a codificação binária do Direito em lícito ou ilícito, ou, simplesmente, em "Direito" (Recht, ius) e "Não Direito" (Unrecht, iniuria). Tal código é o fator de autolimitação do Direito, circunstância que lhe atribui autonomia, transformando "toda a comunicação em comunicação jurídica" (ROCHA; SCHWARTZ; CLAM, 2013, p. 104).

Logo, para o pleno funcionamento do sistema autopoiético de Direito, Luhmann destaca como ponto-chave um elemento fundamental: a comunicação, considerando a linguagem, ainda, como o meio comunicativo mais importante. Além disso, o sociólogo afirma que a "sociedade é um sistema comunicativamente fechado, pois a comunicação só pode ser produzida por meio da própria comunicação, sendo a linguagem o meio essencial de comunicação, responsável por garantir a regular e contínua autopoiese de toda a sociedade" (PORTUGAL, 2013, p. 6). Por oportuno, André Trindade afirma:

Para a teoria sistêmica, o que deve ser privilegiado em uma sociedade são as comunicações entre os sistemas e seus elementos. $\mathrm{O}$ indivíduo [...] não pode ser considerado elemento formador do sistema social. O que gera o sistema social são as comunicaçóes. $\mathrm{O}$ indivíduo, por sua vez, apenas congrega dois sistemas em um: o sistema orgânico e o nervoso, sendo o sistema nervoso o responsável pela interação social através do processo comunicativo (2007, p. 111).

À primeira vista, o panorama apresentado assemelhar-se-ia com o modelo de ação comunicativa proposta por Jürgen Habermas. Segundo o filósofo alemão, o método da razão discursiva, exteriorizado pela comunicaçáo, é o mecanismo propício para libertar e emancipar os membros componentes da sociedade (NADER, 2014). Nessa ótica, a linguagem assume um papel fundamental, funcionando como um "meio de organização da realidade social por meio da comunidade discursiva" (SILVA, 2007). 
Há, contudo, uma distinção pontual entre os pensamentos de ambos os autores: para Luhmann, são os sistemas sociais que produzem a comunicação, "enquanto os indivíduos atuam nos sistemas psíquicos" (ROCHA; SCHWARTZ; CLAM, 2013, p. 61), ao passo que, na ótica de Habermas, estes últimos são os responsáveis por estimular a linguagem e a correspondente comunicação. ${ }^{2}$

Dadas essas premissas, apenas a título de diferenciar as ideias propostas, convém destacar que, para Luhmann, a estrutura comunicativa apresentada é responsável pela criação das expectativas sociais, cuja finalidade é a garantia da estabilização das relaçóes entre os integrantes da sociedade. Algumas dessas expectativas, ditas normativas, podem ser produzidas pelo Direito, que, na acepção luhmanniana, não se revela como "um simples conjunto de regras, mas como um conjunto de operaçóes fáticas dispostas sobre a forma de comunicaçôes" (PORTUGAL, 2013, p. 8). André Trindade, com precisão, assevera:

Esse processo de interação intersubjetivo é o responsável pela construção de expectativas compartidas entre os indivíduos. A comunicação humana é a aprimoração das expectativas em um ambiente social. Nesse sentido, o Direito é apresentado como o padräo de observância das expectativas de um meio social. No entanto, o indivíduo não fica atrelado aos ditames das expectativas sociais quando busca suprir as suas necessidades (grifamos) (2007, p. 111).

Nesse raciocínio, infere-se que existem inúmeras possibilidades de atuação no ambiente social, tornando-o, consequentemente, um lugar complexo. Ao mesmo tempo, é considerado contingente, haja vista que, para cada possibilidade existente, há outra contrária. $\mathrm{Na}$ sua própria intelecção:

2 Outra distinção reside no fato de que, para Habermas, o consenso é fundamental para a sociedade contemporânea, diferentemente de Luhmann, o qual assevera que o sentido da sociedade é a produçáo de diferença. Nesse diapasão as liçōes de Marcelo Neves: "Pode-se afirmar que Luhmann procura enfatizar empiricamente o dissenso em torno de conteúdos morais na modernidade. Habermas discute a construção do consenso mediante procedimentos com potencialidade normativa universal como característica da modernidade, sem desconhecer a diversidade de conteúdos valorativos" (NEVES, 1996). Vide, também: ROCHA; SCHWARTZ; CLAM, 2013, p. 28. 
Com complexidade queremos dizer sempre que existem mais possibilidades do que se pode realizar. Por contingência entendemos o fato de que as possibilidades apontadas para as demais experiências poderiam ser diferentes das esperadas [...] Em termos práticos, complexidade significa seleção forçada, e contingência significa perigo de desapontamento e necessidade de assumir-se riscos (LUHMANN, 1983, p. 45-46).

Como forma de reduzir a complexidade e prevenir desapontamentos, criam-se normas juridicas, baseadas "num consenso social sobre determinada expectativa em determinado tempo e lugar" (TRINDADE, 2007, p. 116). Dessa forma, as expectativas são generalizadas, originando um sistema de dupla contingência, isto é, de expectativas de expectativas, que equivale a dizer: se eu espero algo de alguém, esse alguém espera algo de mim (LUHMANN, 1983).

O Direito, portanto, atua entremeio à complexidade e à contingência, e sua função principal é a produçáo de expectativas sociais, mediante critérios racionalmente aceitos pela comunicação social. Além disso, pauta-se num critério de previsibilidade, significando que, uma vez transgredida a norma, e, concomitantemente, a expectativa, será aplicada uma sançáo àquele que desapontou a estrutura de comunicação.

\section{FUNCIONALISMO SISTÊMICO NO DIREITO PENAL}

Günther Jakobs, catedrático da Universidade de Bonn, na Alemanha, é um dos mais notáveis pensadores do Direito Penal na contemporaneidade. Ao lado de seu conterrâneo, Claus Roxin, é um dos expoentes da escola funcionalista no âmbito penal. O raciocínio de ambos, no entanto, diverge estruturalmente, não cabendo, neste espaço, fazer uma análise minuciosa das distinçóes presentes, uma vez que destoa dos objetivos aqui propostos.

Falar da teoria da pena de Jakobs é falar não de um aporte isolado e imutável ao decorrer da elaboração de seu pensamento, mas, sim, de momentos distintos que caracterizaram as conjecturas do insigne penalista. Existem, pelo menos, três fases pelas quais perpassam as reflexóes do proeminente autor, como bem destaca Alexis Couto de Brito: 
Na primeira, a principal finalidade da pena é a influência psicológica nos membros da sociedade para que continuem confiando na norma, ou seja, fiéis ao direito. Em uma segunda fase, Jakobs relega a influência pessoal a um segundo plano (evidentemente por ausência de comprovação prática), e a pena passa a ter a finalidade principal de confirmar a identidade da sociedade na medida em que marginaliza o delito e reafirma a estabilidade normativa, ou seja, a vigência da norma. Em seus últimos textos, Jakobs passa a admitir e até justificar a "dor penal" que carrega a pena, como forma fática de apoio cognitivo ou consolidação cognitiva (2014).

Elaboraremos um estudo voltado basicamente aos dois primeiros momentos pelos quais se estruturou o funcionalismo sistêmico proposto por Jakobs, mencionando, desde já, a adoção de alguns dos pressupostos do pensamento luhmanniano, principalmente no que se refere à noção de expectativas. Estas representam a essência do sistema jakobsiano de Direito Penal e, porque não dizer, as vigas de edificaçáo e sustentação da sociedade complexa.

Deixamos antever, no tópico antecedente, que as expectativas se generalizam com o objetivo de reduzir a complexidade e prevenir desapontamentos. A partir disso, escreve Eduardo Montealegre Lynett, "o sistema social cria certos mecanismos para que os cidadãos possam seguir confiando nelas apesar de sua defraudação”. Desse modo, segundo "a forma como se reage frente a um ocorrido que se apresenta de uma maneira distinta à esperada se fala de expectativas cognitivas ou normativas" (LYNETT, 2005, p. 14).

Na categoria cognitiva "são experimentadas e tratadas as expectativas que, no caso de desapontamentos, são adaptadas à realidade” (LUHMANN, 1983, p. 56). Por derradeiro, exigem-se "medidas que permitam a real assimilação de situaçóes de desapontamento, bastante rapidamente e em sentidos nitidamente apontados" (1983, p. 62). Vale dizer, o abandono à expectativa situada no plano cognitivo, depois de sua defraudação, é o modo satisfatório de se sublevar perante o desapontamento. Isso exige, porém, que se modifique o comportamento, assimilando-o e adaptando-o à nova realidade.

De outro modo, normativas são as expectativas circunscritas "às relaçóes do homem com os demais membros da interação social” (LYNETT, 2005, p. 14), cuja violação não acarreta no seu imediato abandono (LUHMANN, 1983). 
Assim, mesmo no caso de desapontamento da expectativa normativa, deve ser possível demonstrar sua sustentação (LUHMANN, 1983), isto é, que a viga não se rompeu. Para o sociólogo,

[...] o sistema social tem que orientar e canalizar o processamento de desapontamentos de expectativas - e isso náo só para impor eficazmente expectativas corretas (p. ex. normas jurídicas), mas sim para criar a possibilidade de expectativas contrafáticas, que se antecipem a desapontamentos, ou seja: normativas (LUHMANN, 1983, p. 67).

A solução, encontrada no funcionalismo sistêmico jakobsiano, é a redução de expectativas a normas jurídicas, as quais, pode-se afirmar, representam "expectativas de comportamento estabilizadas em termos contrafáticos” (LUHMANN, 1983, p. 57). Uma vez contrariada a norma, como decorrência lógica da resposta contra o fato, impóe-se uma pena ao transgressor. Destarte, a pena, para Jakobs, é o instrumento apto à manutenção da vigência da norma, e, por consequência, da própria expectativa como modelo de orientação social (JAKOBS, 1997), daí a conclusão do autor que "uma norma vigora, enquanto possa ser seguida como válida e o seu desrespeito não, ou seja, enquanto ela, e não seu desrespeito configure a estrutura da sociedade" (JAKOBS, 2005, p. 48).

Dessa forma, a pena tem a função de prevenir desapontamentos, mantendo a expectativa incólume e afirmando que, apesar da decepção, que é momentânea, ela permanece possível de ser manifestada (JAKOBS, 2008), orientando o padrão de convivência social, ou, em outros termos, a própria identidade social (LUHMANN, 1983). Esse processo tem por objetivo evitar o abandono à expectativa normativa e a conseguinte adaptação à situação fática, por meio de um aprendizado cognitivo. É o que conclui Alexis Couto de Brito:

Porque se deve aplicar uma pena? Se uma infração à norma fica sem punição, pode-se iniciar um processo de aprendizagem (cognição) que causará a erosão da norma. A pena é uma reafirmação da vigência da norma, pois não se precisa aprender com a quebra da expectativa, mas sim reafirmar as expectativas frustradas (2014). 
$\mathrm{Na}$ perspectiva jakobsiana, cumpre lembrar, o delito é visto como uma fatha de comunicação. A comunicação é insculpida em congruência com os sistemas sociais, ex vi da proposta de Luhmann, configurando, assim, a identidade social. Nesse diálogo o Direito Penal, quando aplica a pena, confirma essa identidade social, dado que a sua prestação consiste em contradizer "a contradição das normas determinantes da identidade da sociedade" (JAKOBS, 2003b, p. 4) mediante a negação de uma negação. Com acuidade disciplinam Peñaranda Ramos, Suárez González e Cancio Meliá:

A pena serve precisamente para que as expectativas normativamente fundadas não
fiquem anuladas por sua defraudação, no caso concreto; para sua manutençâo
"contrafática", isto é, para sua manutenção, apesar da evidência de sua defrau-
dação de fato, mediante a definição como defeituosa da conduta do autor, e não
da expectativa de que este se comportasse conforme a norma. A pena consiste,
portanto, em uma contradição da violação da norma que se executa a custa de seu
autor (grifamos) (2013, p. 20).

Percebe-se, pois, que, à teoria funcionalista sistêmica de Direito Penal é importada a dialética hegeliana: o sujeito, ao praticar um delito, nega a existência da norma, esboçando uma particular visão de mundo. Ao ser abalada a expectativa, o Estado deve, como consequência lógica, aplicar uma pena ao infrator. O objetivo, por essa razão, é restabelecer a vigência da norma outrora ignorada, mantendo intactas as hastes normativas que sustentam a sociedade. Assim sendo, a norma é considerada a tese; o delito, a antítese; e a pena, a síntese (LYNETT, 2005).

O funcionalismo sistêmico lastreia-se, então, em critérios de prevenção geral positiva, pois, se a norma é a raiz do tronco social, que estabelece expectativas gerais de comportamento e caracteriza a própria identidade social, é a aplicação da pena à sua violação que a manterá solidificada. Nessa perspectiva, Cristiano Tutikian aduz:

Quando produzidas conseqüências (sic passim) desfavoráveis em razão de violação de uma norma, e quando essas conseqüências, em face da estabilidade do sistema, deixam de ser toleráveis, intervém a reaçáo punitiva. Por isso, sua função primária é de prevenção positiva; daí ser a pena prevençáo-integração no 
sentido de que sua função primária é a de exercitar o reconhecimento da norma e a fidelidade perante o direito por parte dos membros da sociedade (grifo do original) (TUTIKIAN, 2008).

É “prevenção geral porque pretende-se (sic) produzir um efeito em todos os cidadãos; positiva, porque esse efeito não se pretende que consista em medo diante da pena, e sim em uma tranquilização no sentido de que a norma está vigente”, isto é, "de que a vigência da norma, que se viu afetada pelo fato, voltou a ser fortalecida pela pena"(JAKOBS, 2012, p. 42-43), buscando, por via de consequência, a estabilização de um processo comunicativo mediante a imposição de uma pena, propiciando à sociedade uma espécie de feedback como resposta do Estado em relação ao delito ocorrido. A propósito, vide o que afirma Dal Dosso:

La pena en la concepción de Jakobs es prevención general positiva o integradora, que no tiene por finalidad intimidar a los futuros delincuentes para que no delincan, sino que se dirige a la generalidad para asegurar las expectativas de comportamiento establecidas o determinadas normativamente, que permiten la vida social. La pena entonces no persigue evitar que se vuelva a delinquir, sino restablecer la vigencia perturbada de la norma, restableciendo su confianza en ella (ejercicio de confianza en la norma) (2011, p. 47).

Em razão disso, a pena não visa a produzir efeitos acautelatórios contra condutas individuais. Pelo contrário, dirige-se a dinâmicas sociais ou coletivas. Por esse motivo é que a pena deve prevenir, basicamente, os efeitos negativos do delito para o sistema social em que ele ocorreu.

Grande parte dos estudiosos da dogmática penal critica o modelo funcional-sistêmico elaborado por Jakobs. Maldizeres que, no mais das vezes, carecem do conhecimento global da estrutura edificada pelo catedrático, cuja teoria não procura a proteção de bens jurídicos, mas, sim, a manutenção da vigência da norma como modelo de orientação social. Esse critério de prevenção geral positiva, pois, é o principal ponto controvertido do funcionalismo jakobsiano, pelo qual se acendem os mais variados dissabores doutrinários, entretanto sem a devida reflexão, permissa vênia. 
Em regra, sim, cabe à pena a função de confirmar a identidade social, porém, como adverte Jakobs, "en la teoría de la prevención general positiva no se trata, pues, de considerar en todo caso adecuada únicamente la pena y no otra reacción” (1997, p. 14, nota no 14). Desse modo, a pena não é aplicada indistintamente, em qualquer caso e sem critérios axiológicos, uma vez que existem outros mecanismos capazes de sustentar as vigas da identidade social e, assim, garantir a vigência da norma: os assim chamados equivalentes funcionais (JAKOBS, 2008). O eminente penalista cita como exemplo a própria indenização do dano:

Especialmente, la indemnización resarcitoria para reparar las consecuencias del delito (y con mayor energía la indemnización por daño personal: Schmerzengeld) confirma la vigencia de la norma infringida. [...] La importancia de la infracción de la norma no depende de la magnitud de los dańos que hán de resarcirse [...]. A pesar de ello, el deber de resarcimiento puede bastar en el caso concreto como consecuencia del delito; incluso, en algunos delitos puede ser para la víctima más adecuado que prevalezca el deber de resarcimiento sobre la pena (JAKOBS, 1997, p. 16-17).

Faz-se, portanto, a seguinte conclusão provisória: o crime corresponde, de acordo com o Direito Penal embasado num sistema construído a partir de expectativas e com normas fundantes de orientação da conduta humana, a uma ruptura da identidade social. A reconstrução dessa identidade pressupóe a aplicação de uma pena ou outra reaçáo adequada ao delito praticado, como forma de confirmar a força vinculante da norma infringida.

\section{A IMPUTAÇÃO OBJETIVA COMO REALIZAÇÃO DA AÇÃO}

Para Jakobs, a ação é um ato comunicativamente relevante (JAKOBS, 2012). Essa máxima revela que o conteúdo da ação não é encontrado na concepção do sujeito sobre o fato, ou, ainda, com fundamento em estruturas pré-jurídicas, mas, sim, no interior da própria sociedade, com base naquilo que é racionalmente aceito, como ressalta Lynett, que acrescenta: 
A elaboração no conceito de ação com base na comunicação implica que é relevante o esquema social de interpretação do ocorrido, porque, se as normas são "estruturas reflexivas de expectativas", a relação de comunicação sempre se define pelo contexto. As condutas se determinam de acordo com a expectativa de expectativas, é dizer, sobre expectativas recíprocas: eu realizo minha conduta de acordo ao que os outros esperam de mim (2005, p. 19).

Além disso, concebe-se uma expressão de sentido à ação, de que a norma desrespeitada não é a máxima reitora. Nos comentários de Jakobs, a expressão de sentido corresponde ao "comportamento que conduz ou pode conduzir a um resultado delitivo externo e evitável, se este comportamento, de acordo com um juízo comunicativamente relevante, é ou poderia ser a razão determinante do delito externo" (JAKOBS, 2012, p. 77). Desse modo, cria-se de maneira evitável uma condição de resultado, de tal modo que essa condição é, ou poderia chegar a sê-lo, a razáo determinante do resultado, de acordo com um juízo comunicativamente relevante. Conclui Jakobs:

Com isso, o autor expressa que a norma que se opóe a seu comportamento para ele não é a máxima de comportamento reitora (essa é a formulação da ação como expressão de sentido); esse sentido introduzido no mundo é o efeito especificamente jurídico-penal (JAKOBS, 2012, p. 77).

Essa expressão de sentido defeituosa, interpretada de acordo com um esquema social, é determinada pela imputação objetiva do comportamento. Antes da análise dos institutos dogmáticos arquitetados por Jakobs, convém destacar que, para o ilustre penalista, cada cidadão é detentor de um papel social, este entendido como "um sistema de posiçóes definidas de modo normativo, ocupado por indivíduos intercambiáveis; trata-se, portanto, de uma instituição que se orienta com base nas pessoas" (JAKOBS, 2014, p. 20).

A violação do papel é o marco inicial da (suposta) responsabilidade penal (JAKOBS, 2003b). Não se trata, assim, de (des)valorar a ação do sujeito em si, mas a ação do portador de um papel, com base na orientação normativa correspondente à funçáo exercida pelo indivíduo na sociedade (JAKOBS, 2014). Esse pressuposto 
remete à ideia de solidariedade social aplicada ao Direito, pela qual a liberdade do agir humano corresponde ao cumprimento do seu dever. Partidário dessa corrente, Léon Duguit consigna:

Estabelecido o direito objetivo na solidariedade social, o direito "subjetivo" daí deriva, direta e logicamente. E sendo todo indivíduo obrigado pelo direito objetivo a cooperar na solidariedade social, resulta que ele tem o "direito" de praticar todos aqueles atos com os quais coopera na solidariedade social, refutando, por outro lado, qualquer obstáculo à realizaçáo do papel social que lhe cabe. [...] Não são os direitos naturais, individuais, imprescritíveis do homem que fundamentam a regra de direito imposta aos homens em sociedade. Mas, ao contrário, porque existe uma regra de direito que obriga cada homem a desempenhar determinado papel social, é que cada homem goza de direitos - direitos que têm assim, por princípio e limites, o desempenho a que estấo sujeitos (DUGUIT, 2009, p. 42-43).

Para que se possa afirmar, no entanto, que determinada conduta é típica perante o ordenamento jurídico, com base nas expectativas normativas racionalmente reconhecidas, só o rompimento do papel não basta; é preciso, concorrentemente, que a ação - ou omissão ${ }^{3}$ - se realize em descompasso com os quatro institutos jurídico-penais delineados por Jakobs: risco permitido, princípio de confiança, âmbito de responsabilidade da vítima e proibição de regresso.

Risco permitido é aquele aceito pela sociedade e decorre de seu próprio progresso, "especialmente no que tange às invençóes de novas técnicas e aparelhos num sem-número de setores" (JESUS, 2000, p. 39). Corresponde às inovaçôes tecnológicas e automobilísticas, exempli gratia, que, apesar de representarem riscos, são toleradas pela sociedade, de sorte que sua paralisação representaria, também, a neutralização do próprio desenvolvimento social (JAKOBS, 2014).

3 Não realizaremos, aqui, distinção entre ação e omissão, em consonância com a proposta de Jakobs, para o qual "a resposta à pergunta sobre se um comportamento tem ou não significado delitivo depende, por conseguinte, tanto na comissão como na omissão, das mesmas regras" (JAKOBS, 2003a, p. 29-30). 
O princípio de confiança orienta que, nas relaçóes sociais, as pessoas devem agir na confiança de que as outras se comportarão da igual forma, de acordo com as expectativas normativas comunicativamente reconhecidas; não deixa de configurar, desse modo, um sistema de dupla contingência.

Dito isso, "as hipóteses de aplicação do princípio da confiança não deixam de formar parte do grupo de casos nos quais o risco permitido requer uma adaptação às circunstâncias concretas" (PEÑARANDA RAMOS; SUÁREZ GONZÁLEZ; CANCIO MELIÁ, 2013, p. 78), a exemplo do tráfego viário, que, não obstante caracterize um risco permitido, há, ainda que abstratamente, uma relação de confiança recíproca entre os condutores.

Em certos casos, o curso lesivo se origina em virtude da responsabilidade da própria vítima. Nessas situaçóes, consoante enfatiza Jakobs, se a vítima "atuou em seu próprio risco, e quando a vítima é a única responsável, as demais pessoas desempenharam corretamente seu papel como pessoas fiéis ao ordenamento jurídico" (2005, p. 36-37), porquanto não desvalorada juridicamente a respectiva conduta (JAKOBS, 2014).

Além do mais, as relações que formam um vínculo entre as pessoas, por vezes originam atividades consideradas não permitidas. Não se pode afirmar, contudo, que viola seu papel o indivíduo que, na relação, praticou uma conduta inofensiva, responsável pelo início de conduta diversa por outro agente, que, por sua vez, ofende o regramento jurídico, posto que "uma ação cotidiana inicial correta não conduz seu autor à responsabilidade por condutas posteriores ilícitas" (JESUS, 2000, p. 49). Há, portanto, uma proibição de regresso (JAKOBS, 2014).

Resumidamente, são estes os quatro institutos jurídico-penais que, na visão de Jakobs, delimitam a tipicidade do comportamento na esfera penal, comportamento este, conforme assinala o autor, vinculado a papéis (JAKOBS, 2014). Na síntese do eminente catedrático:

[...] quem leva a cabo uma conduta dentro do risco permitido, permanece dentro de seu papel; quem presta uma contribuição a quem atua a risco próprio, também; quem contribui com quem atua em seu próprio risco, também; quem presta um serviço estereotipado, e náo se adapta aos planos delitivos de outras pessoas, náo participa criminalmente na execução desses planos: existe 
uma proibição de regresso e igualmente permanece no papel de cidadão fiel ao direito, aquele que, por exemplo, no trânsito viário, confia que os outros se conduzirão de modo correto: princípio de confiança (JAKOBS, 2005, p. 37-38).

Em suma: o Direito Penal, na ótica jakobsiana, detém a função de manter a vigência da norma como modelo de orientação social, baseando-se em expectativas generalizadas que orientam a atuaçáo das pessoas no sistema normativo, uma vez que, cada qual, é portadora de um papel. A desvirtuação desse papel deve ser visualizada conforme um esquema social de interpretaçáo, naquilo que é racionalmente aceito pela sociedade pelos mecanismos de comunicação. Somente quando uma ação - ou omissão - não se apresentar de acordo com as expectativas normativas é que se abre a possibilidade de intervenção penal, que se baseará nas estruturas dogmáticas - risco permitido, princípio de confiança, responsabilidade da vítima e proibição de regresso - para diagnosticar a tipicidade da conduta.

\section{A CORRELAÇÃO ENTRE NORMA E IMPUTAÇÃO OBJETIVA}

A sociedade é estruturada em expectativas de comportamentos generalizadas em normas. Estas representam o vínculo entre o sujeito e o ordenamento jurídico, ou seja, a fidelidade do indivíduo ao Direito enquanto portador de um papel. A ruptura desse papel acarreta a ruptura da própria expectativa, da norma fundante de orientação social. E como se rompe uma expectativa senão por uma ação, ou por uma omissão, que seja? E o que determina que essa ação seja típica e comunicativamente relevante, que não a imputação objetiva do comportamento? Eis, em linhas gerais, a primeira conclusão provisória sobre a correlação entre norma e imputação objetiva na teoria de Jakobs. $\mathrm{O}$ assunto requer mais especificaçóes.

Conforme exposto em linhas anteriores, para Luhmann a sociedade é um lugar complexo, imerso de possibilidades e expectativas recíprocas, que podem, ou não, serem atendidas. Daí se afirmar que é contingente, pois para cada comportamento há outro diverso, que ora pode corresponder ao esperado, ora não.

É preciso, então, estabelecer uma identidade social, que, para Jakobs, funda-se em normas de condutas que constituem a própria sociedade (JAKOBS, 2003b). Ao Direito Penal incumbe a missão de manter hígida tal identidade social, confirmando 
a norma como modelo de orientação. Essa ideia dissocia-se de realidades utópicas, pois o Direito Penal é elaborado para uma sociedade concreta, e não imaginária (JAKOBS, 2003b). Desse modo, torna-se a manutenção da norma, e não a proteção de bens jurídicos, o primado fundamental do Direito Penal. Esta ideia remete a Welzel, conforme aponta Bernardo Feijóo Sanchez:

[...] o direito fundamental de considerar como fundamento do Direito penal a proteção de bens jurídicos é que dita doutrina os concebia como desintegrados na vida social real, mas num mundo inabitável, sem função alguma [...] Welzel insistiu em deixar claro que os bens jurídicos somente existem enquanto cumprem uma função na vida social. Não são entes situados num mundo ideal [...] 2003, p. 133-134).

Logo, é a norma que representa a realidade, e é a ela que o Direito Penal se reporta, justamente para promover a concreção da sociedade complexa diante dos fatores contingenciais. Desta forma, a expectativa normativa será transgredida por uma ação humana decorrente da violação do portador de um papel. Cabe ao Direito Penal, por conseguinte, verificar se dita ação é objetivamente imputável e configura, de acordo com um juízo comunicativamente relevante, a desautorização de uma norma, para, posteriormente, aplicar-se a pena ou a reação respectiva com o fim de mantê-la vigente (JAKOBS, 2003b). Jakobs não deixa dúvidas ao afirmar que:

Esta contradicción a la norma por medio de una conducta es la infracción de la norma. Una infracción normativa es, por tanto, una desautorización de la norma. Esta desautorización da lugar a un conflicto social en la medida en que se pone en tela de juicio la norma como modelo de orientación. La determinación exacta de cuándo concurre una contradicción a la norma es el problema de la teoría de la imputación, en especial de la imputación en calidad de comportamiento típico y antijurídico (1997, p. 13).

Em virtude disso, a infração normativa somente será assim considerada quando passível sua imputação ao tipo objetivo referente ao crime praticado. Sendo impossível a imputação, forçoso concluir que não houve a desautorização da norma orientadora de conduta social, uma vez que inexistente uma expressão de 
sentido defeituosa, de acordo com juízos de relevância comunicacional. A norma, portanto, não foi rompida, e nenhum mecanismo precisa demonstrar sua vigência (JAKOBS, 2003b).

\section{Com acerto assevera Dal Dosso:}

Aquí se ve claro por qué para Jakobs la teoría de la imputación objetiva no es un mero vínculo entre acción y resultado sino que es la encargada de establecer cuándo estamos frente a una acción jurídico-penalmente relevante, es ella la que afirma la inadecuación social. Quien lleva adelante una obra socialmente irrelevante no le es objetivamente imputable porque falta la perturbación social, falta el quebrantamiento del rol por parte del sujeto y con ello la vigencia de la norma no ha sido afectada. Este suceso, irreprochable desde el punto de vista social, no puede ser considerado acción para el Derecho Penal (grifamos) (2011, p. 52).

Assim sendo, o modelo de prevenção geral positiva proposto por Jakobs não é construído sem critérios axiológicos, com a desmedida aplicação de penas aos delitos praticados. Antes configura um referencial concreto à realidade social, desvinculado de utopias desnecessárias.

Consequentemente, a formulação genérica que corriqueiramente se lê, de que a finalidade do Direito Penal é manter a vigência da norma como modelo de orientação social, deve ser acrescida de pautas dogmáticas mais precisas. Posto isso, pode-se formular a síntese definitiva: uma norma somente será violada por uma ação típica, e ação típica é uma expressão de sentido defeituosa, de acordo com um juízo comunicativamente relevante, que requer uma interpretação social do ocorrido. $\mathrm{A}$ tarefa de desvalorar juridicamente a ação é incumbência da imputação objetiva do comportamento (JAKOBS, 2014), mediante a análise dos institutos dogmáticos do risco permitido, do princípio da confiança, do âmbito de responsabilidade da vítima e da proibição de regresso. Estando em descompasso com estes critérios gerais, pode-se afirmar que a ação é típica e que violou a norma; deste modo, a vigência desta depende da aplicação de uma pena ou de outra reação compatível. Caso contrário, não sendo desaprovada juridicamente, a ação é atípica para o Direito Penal e, por derradeiro, não corresponde à violação de uma norma. 
A finalidade do Direito Penal, portanto, é manter a vigência da norma violada por uma ação típica que corresponde a uma expressão de sentido defeituosa, de acordo com um juízo comunicativamente relevante, mediante a imposição de uma pena ou de outro mecanismo análogo, para, assim, confirmar a identidade social exposta na expectativa normativa fundante da orientação de condutas humanas. É a correlaçáo entre norma e imputação objetiva.

\section{CONCLUSÃO}

O contributo de Günther Jakobs para a dogmática penal é imenso, pois reinventa a forma de pensar o Direito Penal a partir da visáo da sociedade sobre o fato, e não apenas do sujeito que praticou o delito em si. Desta forma, abandonam-se alguns subjetivismos finalistas para incrementar no âmbito da imputação elementos objetivos, que delineiam o comportamento daquele que praticou o delito sob o ponto de vista de um esquema social de interpretação.

Isso implica que o Direito Penal não é estruturado para uma sociedade imaginária, de natureza utópica, mas, sim, para uma sociedade concreta. Nesse sentido, cada pessoa é portadora de um papel, de uma função na condição de membro de um corpo social existente e fatídico, num tronco enraizado perante expectativas normativas, que generalizam padrōes de comportamento e sustentam a construção de uma realidade em comum.

Há situaçóes, no entanto, em que o portador do papel viola uma dessas normas fundantes da convivência social, caso em que será necessária a intervenção do Direito Penal, como forma de manter intacta a identidade que aquela norma proporciona à sociedade em que ela está inserida. Para isso, a vigência da norma será estabilizada por meio da aplicação de uma pena, ou de outra reação adequada, a depender da situação concreta.

É preciso, ainda, saber se a conduta humana que, abstratamente, rompeu a expectativa normativa, é realmente típica. Essa tarefa é da imputação objetiva do comportamento, que, por intermédio dos quatro institutos jurídico-penais 
formulados por Jakobs - risco permitido, princípio da confiança, âmbito de responsabilidade da vítima e proibição de regresso - fornecerá o subsídio necessário para se concluir que a ação é penalmente relevante.

Constatada a tipicidade da conduta, tornar-se-á possível a intervenção do Direito Penal, posto que a este subsistema jurídico cabe a missão de manter a vigência da norma como modelo de orientação social; atípica a conduta, não cabe falar em rompimento da expectativa normativa, porquanto dispensável a aplicação de uma pena ou de qualquer outra medida. Existe, consequentemente, uma verdadeira correlaçáo entre norma e imputaçáo objetiva, dado que a violaçáo daquela depende, necessariamente, da análise desta.

Reluzentes maldizeres se acendem, com frequência, à teoria funcionalista-sistêmica, muitos das quais, no entanto, sem a devida reflexão global das proposiçóes construídas por Jakobs. Em grande parte, meros devaneios doutrinários que não buscam compreender uma proposta original, de índole revolucionária.

Óbvio que a crítica de lege ferenda é necessária, porém sustentada de acordo com uma interpretação sistemática do assunto. Não estamos afirmando que concordamos, integralmente, com os pressupostos jakobsianos. Acreditamos, sim, que suas conclusões são de elevada importância na dogmática penal contemporânea e estimulam o debate científico. ${ }^{4}$

Trabalhar com os fundamentos e critérios idealizados por Jakobs, portanto, significa conferir ao Direito Penal uma visão concreta, e não idealizada, aplicável a uma sociedade fatídica, com relações humanas complexas, exteriorizadas com base em papéis dos intervenientes do processo de socializaçáo. Deve haver estímulo ao debate desse novo sistema, pois somente assim será possível compreender a sua significância, importância e complexidade para a dogmática penal contemporânea.

${ }^{4}$ A propósito, excelente ponderação realizada por Bernardo Feijóo Sanchez: "La teoría de la pena de Jakobs es una magnífica teoría científica, entendido esto no en el sentido de que haya que asumirla como válida o correcta, sino que se trata de una teoría que encierra una enorme capacidad para generar ideas nuevas y estimular el debate científico en un tema que hace un tiempo parecía agotado" (2006). 


\section{REFERÊNCIAS}

BRITO, Alexis Couto de. As finalidades da pena em Günther Jakobs. Revista Brasileira de Ciências Criminais, São Paulo, v. 110, p. 15-49, set./out. 2014.

DAL DOSSO, Dario Alberto. Teoría de la Imputación Objetiva. Investigación para la evaluación final correspondiente a la VI Edición del Master Propio en Derecho Penal. Universidad de Sevilla, 2011. Disponível em: <http://master.us.es/cuadernosmaster/8.pdf>. Acesso: 13 ago. 2016.

DUGUIT, Léon. Fundamentos do Direito. Tradução Márcio Pugliesi. São Paulo: Martin Claret, 2009.

FEIJÓO SANCHEZ, Bernardo. Prevención General Positiva. Una reflexión en torno de la teoría de la pena de Günther Jakobs. Anuario de derecho penal y ciencias penales, ISSN 0210-3001, Tomo 59, Fasc/Mes 1, p. 111-134. 2006.

- Teoria da imputaçấo objetiva: estudo crítico e valorativo sobre os fundamentos dogmáticos e sobre a evolução da teoria da imputação objetiva. Tradução Nereu José Giacomolli. Barueri: Manole, 2003.

JAKOBS, Günther. A imputação objetiva no Direito Penal. 5. ed. Tradução André Luís Callegari. São Paulo: Editora Revista dos Tribunais, 2014.

- Ação e omissão no Direito Penal. Tradução Maurício Antônio Ribeiro Lopes. São Paulo: Manole, 2003a.

. Derecho Penal: Parte General. Fundamentos y teoría de la imputación. Traducción Joaquin Cuello Contreras e Jose Luis Serrano Gonzales de Murillo. Madrid: Marcial Pons, 1997.

. Fundamentos do Direito Penal. Tradução André Luís Callegari. São Paulo: Ed. Revista dos Tribunais, 2012.

. O que protege o direito penal: os bens jurídicos ou a vigência da norma? Tradução André Luís Callegari, Nereu José Giacomolli e Lúcia Kalil. In: CALLEGARI, André Luís et al. Direito penal e funcionalismo. Coordenação: André Luís Callegari e Nereu José Giacomolli. Porto Alegre: Livraria do Advogado, 2005.

Sociedade, norma e pessoa. Tradução Maurício Antônio Ribeiro Lopes. São Paulo: Manole. 2003b.

- Tratado de Direito Penal: Teoria do Injusto Penal e da Culpabilidade. Tradução

Gercélio Batista de Oliveira Mendes e Geraldo de Carvalho. Belo Horizonte: Del Rey, 2008. 
JESUS, Damásio E. de. Imputação objetiva. São Paulo: Saraiva, 2000.

LYNETT, Eduardo Montealegre. Introdução à obra de Günther Jakobs. Tradução André Luís Callegari, Nereu José Giacomolli e Lúcia Kalil. In: CALLEGARI, André Luís et al. Direito penal e funcionalismo. Coordenação: André Luís Callegari e Nereu José Giacomolli. Porto Alegre: Livraria do Advogado, 2005.

LUHMANN, Niklas. La sociedad de la sociedad. Tradução do alemão para o espanhol Javier Torres Nafarrete. México: Herder, 2007.

. Sociologia do Direito I. Tradução Gustavo Bayer. Rio de Janeiro: Edições Tempo Brasileiro, 1983.

NADER, Paulo. Filosofia do Direito. 22. ed. Rio de Janeiro: Forense, 2014.

NEVES, Marcelo. Luhmann, Habermas e o estado de direito. Lua Nova (on-line), n. 37, p. 93-106. 1996. Disponível em: <http://dx.doi.org/10.1590/S0102-64451996000100006>. Acesso: 23 jun. 2016.

PEÑARANDA RAMOS, Enrique; SUÁREZ GONZÁLEZ, Carlos; CANCIO MELIÁ, Manuel. Um novo sistema do Direito Penal: consideraçóes sobre a teoria da imputaçâo objetiva de Günther Jakobs. Tradução André Luís Callegari e Nereu José Giacomolli. 2. ed. Porto Alegre: Livraria do Advogado, 2013.

PORTUGAL, Daniela. A autopoiese no Direito e o Funcionalismo Sistêmico de Günther Jakobs na Aplicação da Lei Penal. Cadernos do Programa de Pós-Graduação em Direito/UFRGS, Porto Alegre, vol. VIII, n. 2, 2013.

ROCHA, Leonel Severo; SCHWARTZ, Germano; CLAM, Jean. Introdução à teoria do sistema autopoiético do Direito. 2. ed. Porto Alegre: Livraria do Advogado, 2013.

SILVA, Beclaute Oliveira. Teoria discursiva e seus reflexos no direito segundo o pensamento de Habermas. Revista de Informação Legislativa, Brasília, v. 44, n. 175, p. 189-203, jul./set. 2007. Disponível em: <http://www2.senado.leg.br/bdsf/item/id/137588>. Acesso: 11 jun. 2016. TRINDADE, André Fernando dos Reis. Os direitos fundamentais em uma perspectiva autopoiética. Porto Alegre: Livraria do Advogado, 2007.

TUTIKIAN, Cristiano. Prevenção geral positiva e proteção de bens jurídicos: possibilidades e contradições no Estado Democrático de Direito. Revista de Informação Legislativa, Brasília, v. 45, n. 177, p. 243-255. 2008. Disponível em: <http://www2.senado.leg.br/bdsf/item/ id/160327>. Acesso: 9 ago. 2016. 